\title{
Santa Teresa de Jesús como modelo de vida para las místicas novohispanas. La obra de Alonso Ramos sobre Catarina de San Juan
}

\section{Santa Teresa of Jesus as Example for the Novo Hispanic Mystics. The Work of Alonso Ramos about Catarina de San Juan}

\section{Gisela von Wobeser}

Universidad Nacional Autónoma de México

Instituto de Investigaciones Históricas

MÉXICO

gisela@unam.mx

[Hipogrifo, (issn: 2328-1308), 4.2, 2016, pp. 101-112]

Recibido: 01-12-2015 / Aceptado: 02-03-2016

DOI: http://dx.doi.org/10.13035/H.2016.04.02.09

Resumen. La vida y la obra de Santa Teresa de Jesús tuvieron una gran influencia sobre el ambiente espiritual en Nueva España, al posibilitar una relación más íntima y directa de las mujeres con Dios y contribuir a la proliferación de monjas y beatas místicas. En la obra Prodigios de la omnipotencia y milagros de la gracia en la vida de la venerable sierva de Dios Catharina de San Joan, Alonso Ramos escribe la biografía de Catarina de San Juan, una esclava manumisa considerada santa, a la que en muchos pasajes equipara con santa Teresa. El propósito de Ramos fue crear un modelo de vida femenino basado en la espiritualidad y los valores teresianos.

Palabras clave. Nueva España, hagiografía, santa Teresa, misticismo, místicas femeninas, santidad femenina, Alonso Ramos, Catarina de San Juan, Inquisición.

Abstract. The life and work of Santa Teresa of Jesus had a great influence on the New Spain spiritual atmosphere by enabling a more intimate and direct relationship of women with God and contribute to the proliferation of nuns and beatified. In the Wonders of the Omnipotence and Miracles of the Grace in the life of the Venerable Servant of God Catharina of San Joan, Alonso Ramos writes the biography of 
Catarina of San Juan, a free slave considered saint, to whom in many passages compares with Santa Teresa. The purpose of Ramos was to create a female life model based on Teresian spirituality and values.

Keywords. New Spain, Hagiography, Saint Teresa, Mysticism, Female Mystics, Female Holiness, Alonso Ramos, Catarina de San Juan, Spanish Inquisition.

En 1692 la Inquisición española colocó el primer tomo de Prodigios de la omnipotencia y milagros de la gracia en la vida de la venerable sierva de Dios Catharina de San Joan en el Índice de libros prohibidos, de Alonso Ramos, por contener «revelaciones, visiones y apariciones inútiles, inverosímiles, llenas de contradicciones y comparaciones impropias, indecentes y temerarias, y que saben a blasfemias [... sin más fundamento que la vana credibilidad del autor $»^{2}$. Este acto significó un duro golpe para el clero novohispano, esperanzado en que la obra, que comprendía tres tomos, formara parte del expediente para postular a la poblana Catarina de San Juan como candidata a santa. Catorce dictaminadores, entre ellos cuatro calificadores del Santo Oficio de la Inquisición, habían aprobado la obra y habían constatado que no contenía nada que se opusiera a la fe católica ni a las buenas costumbres. Por el contrario, en los dictámenes alabaron la maestría del autor y exaltaron las virtudes de Catarina, a quien llegaron a comparar con las santas Rosa de Lima, Teresa de Ávila y Catalina de Siena. La divergencia de opinión entre los dictaminadores novohispanos y las autoridades inquisitoriales españolas resulta desconcertante, pero, en aquella época, estos desacuerdos eran comunes porque la frontera ente la herejía y la santidad era estrecha y porque resultaba difícil comprobar la autenticidad de los milagros, como se ejemplifica con la propia vida de santa Teresa de Jesús y la de san Juan de la Cruz, quienes fueron perseguidos por la Inquisición y pocos años después de sus muertes, canonizados.

Alonso Ramos, el autor de Los prodigios de la omnipotencia y milagros de la gracia en la vida de la venerable sierva de Dios Catharina de San Joan, fue un destacado teólogo, miembro prominente de la Compañía de Jesús, que llegó a ser rector de los colegios de la Compañía de Mérida, del Espíritu Santo en Puebla y de la Profesa en México. Como culminación de su trayectoria escribió esta biografía hagiográfica sobre Catarina de San Juan, a quien consideraba santa ${ }^{3}$. Además de

1. La obra se editó en tres volúmenes, que aparecieron sucesivamente en 1689, 1690 y 1692 . Hay una versión facsimilar de los tres tomos, con el sello del Centro de Estudios de Historia CONDUMEX -Sociedad Mexicana de Bibliófilos A.C., que salió a la luz en 2004

2. Maza, 1991, p. 35. Francisco de la Maza fue el pionero en las investigaciones sobre Catarina de San Juan. Posteriormente, otros autores han indagado en el tema, a saber, Antonio Rubial, Gauvin Alexander Bailey, Kathleen Myers, Ronald J. Morgan, Robin Ann Rice y Gisela von Wobeser.

3. Obra inmersa en un contexto propiciatorio, cuya mixtura fue resultado de las políticas papales de Urbano VIII y la «religiosidad barroca» afecta a las «manifestaciones de lo divino» (hechos milagrosos, reliquias, imágenes, etc.) Antonio Rubial clasifica la literatura hagiográfica novohispana en cuatro rubros. El tercero, al cual pertenece el texto de Ramos, abarca los años de 1640 a 1700. La singularidad de dicho periodo radica en la inclusión de nuevos personajes y modelos de santidad, entre los que se cuentan las mujeres laicas como Catarina de San Juan. Todo ello bajo un trasfondo de gestación iden- 
contribuir al mencionado propósito de nutrir el expediente para la canonización de Catarina, Ramos se propuso crear un modelo de vida para las mujeres deseosas de transitar por el camino de la perfección y lograr la salvación de sus almas.

Con cerca de mil páginas, Los prodigios de la omnipotencia es una de las piezas maestras de la literatura novohispana, en tanto que nos ofrece un mar de posibilidades para el análisis histórico. Resalta por la riqueza del lenguaje, las disquisiciones teológicas del autor, la información que proporciona sobre la vida cotidiana, la descripción de las prácticas religiosas y de la mentalidad de la época, y por la detallada representación de las visiones, sentimientos, arrobos, premoniciones y raptos de la biografiada. La enriquecen los dictámenes que preceden a cada tomo, escritos que permiten conocer el contexto religioso y cultural en el cual surgió la obra.

Esta obra permaneció casi desconocida durante los siglos XVIII, XIX y una parte del XX debido a que la Inquisición la prohibió en 1696 y se confiscaron y destruyeron casi todos los ejemplares. Sin embargo, algunos tomos aislados se conservaron en repositorios en México, en Estados Unidos y en Europa, y el Centro de Estudios de Historia de México Carso adquirió un ejemplar completo, que anteriormente había pertenecido al Colegio de san Pedro y san Pablo de la ciudad de México.

La vida de Catarina de San Juan fue azarosa. Llegó a Puebla con aproximadamente diez años de edad, como esclava del acaudalado mercader Miguel Sosa. Provenía de algún país oriental, donde fue capturada por tratantes portugueses y posteriormente puesta a la venta en el mercado de esclavos de Filipinas. En casa de los amos aprendió los fundamentos de la religión católica, pero permaneció iletrada e inculta y nunca pudo hablar correctamente el castellano. Durante los años de su esclavitud se distinguió por el buen desempeño de sus labores, así como por su virtud, su devoción hacia Jesucristo y María, y su apego a la religión católica. Después de recuperar su libertad y de quedar viuda se convirtió en beata 4 . Se distanció de las actividades y placeres mundanos, se recluyó en una modesta habitación y se dedicó a hacer el bien a sus semejantes. Practicó el ascetismo como vía para llegar a Dios y tuvo numerosas experiencias místicas que relató a sus confesores. Alonso Ramos, el último de ellos, quedó deslumbrado por su personalidad y la creyó una santa. Con el propósito de escribir su biografía, tomó notas puntuales de las revelaciones que ella le hizo en el confesionario, mismas que constituyen la base para la obra que nos ocupa. Como era propio de las hagiografías, Ramos no pretendió hacer una reconstrucción histórica de su vida sino realizar una biografía idealizada, en la cual destacan sus virtudes y los sucesos sobrenaturales que le ocurrieron.

titaria, donde la constatación de prodigios en suelo novohispano a través de hombres y mujeres de vida ejemplar equiparaba a Nueva España con el Viejo Mundo, colmando de sentido a estas tierras y anexándolas de grandilocuente manera a la historia ancestral del cristianismo (Rubial García, 2008, pp. 26-27). 4. Cabe aclarar que la acepción de «beata» empleada a lo largo de la investigación, hace referencia a la expresión coloquial con la que se denominaban a las mujeres de profusa vida religiosa y no a la tercera etapa en los escalafones de canonización (siervo de Dios, venerable, beato y santo). Sería por completo equívoco, ya que Catarina de San Juan jamás obtuvo ese mérito. 
Hacia fines del siglo XVII, las principales ciudades americanas aspiraban tener santos propios que les confirieran prestigio y constituyeran intermediadores entre sus habitantes y Dios 5 . Lima logró, en 1671, la canonización de la terciaria dominicana Isabel Flores de Oliva, conocida como Rosa de Lima y, en 1679, la beatificación de Toribio de Mogroviejo. Otras ciudades tenían candidatos a santos, algunos de ellos aceptados por la Sagrada Congregación de Ritos en Roma. Quito contaba con la beata Mariana de Jesús, conocida como la Azucena de Quito; México, con el ermitaño Gregorio López y el misionero franciscano Antonio Margil de Jesús, y Puebla, con Sebastián de Aparicio, Isabel de la Encarnación, María de Jesús Tomellín y Juan de Palafox, a los que ahora se sumaba Catarina de San Juan.

Esta multiplicación de vidas «santas» se debió en gran medida a la influencia de santa Teresa de Jesús. Gracias a la temprana publicación de sus obras (1588), aunada a la creciente popularidad a causa de su rauda canonización (1622), los escritos de santa Teresa, tanto impresos como manuscritos, tuvieron una amplísima distribución por todos los dominios de la monarquía hispánica. Como bien advierte Doris Bieñko, las biografías sobre la monja avileña impresas en la Península constituyeron un «vehículo de propagación del modelo de su vida». Por ello, ante esta proliferación de textos, se erigió por todo el orbe ibérico un modelo teresiano que se trocó en paradigma escritural y referencia de espiritualidad. Así, monjas y beatas se apropiaron de dicho modelo, llevándolo a la práctica. Y también fue empleado por los guías espirituales, como en el caso de Ramos con Catarina, con el fin de equiparar virtudes y justificar el halo de santidad que enaltecía a su confesada6 ${ }^{6}$.

Así, a cien años de su muerte y cincuenta de su canonización, santa Teresa era una figura muy reconocida en el ambiente espiritual hispánico ${ }^{7}$ y una de las santas más reverenciadas en Nueva España ${ }^{8}$. A través de sus obras propuso una nueva manera de concebir la religiosidad, fincada en la introspección y la relación directa con Dios. Su ejemplo constituía una oportunidad de actuación, realización y afirmación personal para las mujeres, en una sociedad en la que tenían pocos campos de acción?. Dado que sus obras El Libro de la vida y El castillo interior, conocido también como Las moradas, se leían en muchos conventos femeninos y beaterios,

5. Joseph Gómez de la Parra, en Ramos, Primera parte de los prodigios de la omnipotencia y milagros de la gracia en la vida de la venerable sierva de Dios Catharina de San Joan, s/f. El calificador del Santo Oficio fray Francisco de Ávila anota que en su siglo muchas «mujeres ilustres» habían destacado en Puebla y menciona Isabel de la Encarnación, a María de Jesús Tomellín y a Catarina. Francisco de Ávila, en Ramos, Primera parte de los prodigios de la omnipotencia y milagros de la gracia en la vida de la venerable sierva de Dios Catharina de San Joan, s/f.

6. Bieñko de Peralta, 2014, pp. 167-168.

7. En 1627 fue nombrada patrona de España por Felipe IV.

8. Agustín de la Madre de Dios, 1984, pp. 142, 150, 213, 379; Gómez de la Parra, 1992, p. 152, y Sigüenza y Góngora, 1985, pp. 159, 177, 186, 331.

9. La fundación de conventos femeninos de carmelitas descalzas contribuyó a la difusión de las obras y del pensamiento de santa Teresa. A finales del siglo XVII existía el de San José de Puebla, el de igual nombre de la ciudad de México; el de Santa Teresa de Guadalajara y el de Santa Teresa la Nueva, en la ciudad de México (Ramos, 1997, pp. 57-83). 
muchas mujeres trataron de emular su trayectoria y su apasionada relación con Jesucristo e imitaron sus experiencias místicas ${ }^{10}$.

Fenómenos como la transverberación fueron muy imitados ${ }^{11}$. La beata toluqueña María Josefa de la Peña, que portaba el hábito carmelita, describe su experiencia de la siguiente manera: «Estando así vi a un serafín de los más allegados a Dios y más encendidos en su divino amor. Éste traía en las manos un dardo o saeta y en la punta era de un oro finísimo y unas llamas muy encendidas y llegándose a mí me metió el dardo en el corazón con tanta violencia y fuerza que parecía haberme abierto el corazón medio a medio. Al mismo tiempo vi dos ángeles de menor jerarquía que al tiempo de traspasarme con el dardo caí desmayada y en sus brazos, me sostuvieron al mismo tiempo al sacar el dardo» ${ }^{12}$. Mientras algunas de estas mujeres, como las mencionadas María de Jesús Tomellín e Isabel de la Encarnación, fueron veneradas como santas, otras fueron condenadas por la Inquisición como «falsas místicas» por atribuirles ideas heréticas o por considerar que sus experiencias sobrenaturales eran fingidas o se debían al demonio ${ }^{13}$.

El pensamiento y la obra de santa Teresa devengaron en la fundación de una corriente teológica llamada «teología mística», que muchos tratadistas consideraron uno de los pilares de la doctrina católica ${ }^{14}$. Antonio Núñez de Miranda, un reconocido teólogo jesuita, dictaminador del Santo Oficio de la Inquisición, destaca los méritos de Teresa «en su vida, relaciones, consultas y aprobaciones», junto con «los actos positivos y escritos de su primogénito discípulo san Juan de la Cruz» ${ }^{15}$; Joseph Vidal se refiere a ella como «extática madre y mística doctora» ${ }^{16}$, y el catedrático de prima teología Joseph de Francia Vaca la considera, junto con santo Tomás de Aquino, la máxima autoridad en asuntos de teología mística.

La teología mística, definida como la rama teológica «que interviene en los extraordinarios favores, visiones, raptos y revelaciones con que Dios se comunica a las almas», ejerció una gran influencia en Alonso Ramos y su círculo. La consideraban superior a la teología escolástica. Francia Vaca puntualiza que esta última

10. Rubial García, 1999, p. 177. Este modelo teresiano arraigó profundamente gracias a su rápida resignificación escritural. Según Robin Ann Rice, la hagiografía de la monja avileña transitó prontamente entre los terrenos históricos y los cánones novelescos, traduciendo la complejidad del misticismo en asociación con lo portentoso, código común en el ámbito hispano (Rice, 2014, p. 130).

11. Si bien, varias de estas mujeres autobiografiaron sus experiencias. Otras, como Catarina de San Juan, Francisca Carrasco, Ana Guerra de Jesús, Salvadora de los Santos y Josefa Antonia Gallegos y Díaz, las relataron a terceros, y ellos las dieron a conocer a través de escritos hagiográficos (Rubial García, 2006, p. 31)

12. Jaffary, 2006, p. 148.

13. Rubial García, 1998, p. 6.

14. El hecho que la universidad de Salamanca, la más reconocida de la península, la honrara en 1622 con el doctorado honoris causa le confirió una gran autoridad y la situó en el mismo rango de santo Tomás de Aquino.

15. Núñez de Miranda, en Ramos, Primera parte de los prodigios de la omnipotencia y milagros de la gracia en la vida de la venerable sierva de Dios Catharina de San Joan, s/f.

16. Vidal, en Ramos, Segunda parte de los prodigios de la omnipotencia y milagros de la gracia en la vida de la venerable sierva de Dios Catharina de San Joan, s/f. 
puede aprenderse en los libros, pero la mística solo se adquiere «en la academia del amor de Dios, en la quietud y recogimiento, en la frecuencia de la oración, en los silencios de la contemplación, en la felicidad de la unión y transformación del alma con Dios, en el estado de fruición del verbo». Advierte que una sólida formación en teología escolástica no hace apta a una persona para juzgar los asuntos místicos "porque todas las ciencias son exteriores, esto es vienen como de afuera y entran para ilustrarlos en los entendimientos; pero la mística toda es interior no entra como de fuera al alma, antes sale del alma, de lo interior a lo exterior para manifestarse en obras admirables». Los teólogos escolásticos, al ignorar las «intimidades» con que «Dios favorece a las almas», no pueden entender ni juzgar el «trato interior» mediante el cual Dios se «comunica y se deja gozar de las almas», ya que son «inexplicables». Prosigue diciendo que incluso quienes gozan de las experiencias místicas, no pueden ni saben «decirlas ni conocerlas», a menos que para ello tengan especiales luces del mismo Dios, y refuerza su argumento al decir que sería como tratar de comprender griego o latín sin saber esas lenguas. A los teólogos escolásticos solo les concede la facultad de opinar sobre aquellos aspectos en los que se contravenga la doctrina católica o el dogma, que haya una desviación de lo canónico o se perjudique lo pedagógico ${ }^{17}$.

En la obra que nos ocupa, Ramos atribuye a Catarina de San Juan rasgos de santa Teresa, a pesar de que la personalidad y las circunstancias de vida de ambas mujeres fueron radicalmente diferentes: Teresa fue una monja letrada y culta, perteneciente a una familia acaudalada e influyente, que desempeñó una actividad intelectual y material sorprendente durante toda su vida, mientras Catarina fue lega, perteneció a los estratos bajos de la sociedad y solo tuvo influencia en su entorno inmediato. Sostiene que el camino de la perfección que recorrió Catarina fue similar al de Teresa, ya que estuvo sembrado de penas y «tribulaciones», «mezcladas y alternadas con gustos y delicias del cielo» ${ }^{18}$. Como ella, experimentó los distintos estados místicos: la contemplación, la oración que permite el permanente contacto con Dios, las visiones, las luchas contra el Demonio y una íntima relación con Jesucristo. Asimismo, equipara a las dos mujeres en cuanto que ejercitaron las virtudes en grado «heroico» y practicaron el ascetismo con gran rigor, al portar cilicios, flagelarse y ayunar frecuentemente, entre otras mortificaciones ${ }^{19}$. Afirma que Catarina se rebajaba por humildad, como solía hacerlo la santa, y se denigraba al considerarse perra, bestia, infiel y gusano inmundo ${ }^{20}$. Como Teresa, se mantuvo

\footnotetext{
17. Francia Vaca, en Ramos, Primera parte de los prodigios de la omnipotencia y milagros de la gracia en la vida de la venerable sierva de Dios Catharina de San Joan, s/f.

18. Ramos, Primera parte de los prodigios de la omnipotencia y milagros de la gracia en la vida de la venerable sierva de Dios Catharina de San Joan, parág. 240.

19. Si bien, en sus textos la monja avileña deja entrever que no fue particularmente afecta a las disciplinas corporales, debemos recordar que todo texto está sujeto a múltiples reinterpretaciones. De ahí que en Nueva España, tópicos teresianos como «humillación, mortificación y penitencia» se pudieron traducir en «actos devocionales» de flagelación y privaciones, hasta llegar a los ejercicios más crueles como parámetro de santidad y virtud. De ahí la posibilidad de amalgamar a ambas mujeres dentro de un mismo marco epistémico (Lavrin, 2015, pp. 516-520).

20. Núñez de Miranda, en Ramos, Primera parte de los prodigios de la omnipotencia y milagros de la gracia en la vida de la venerable sierva de Dios Catharina de San Joan, s/f.
} 
casta toda la vida aunque en situaciones más difíciles que ella, porque tuvo que luchar contra un permanente acoso sexual, primero cuando estuvo en manos de los tratantes esclavistas, y después cuando tuvo que defender su castidad frente a su marido, que trataba de forzarla a cohabitar con él, a pesar de que ella había puesto como condición para casarse, la de permanecer virgen.

Ramos asigna a Catarina el papel de esposa escogida, confidente y oráculo de Jesucristo y la coloca en un elevado sitio dentro de la jerarquía celestial, en ocasiones incluso por encima de la virgen María. Dice que «estaba tan unida moral y místicamente con Cristo que era una imagen suya, tan parecida y semejante, que se veía en ella la perfección y hermosura del Verbo humanado, su esposo» ${ }^{21}$. La mezcla entre placer y dolor que implicaba su entrega al Señor se expresa en la transverberación del corazón ${ }^{22}$. A pesar de que acepta que hablaba como «bozal», es decir, utilizaba el lenguaje de los esclavos, pone en su boca disquisiciones teológicas, reflexiones profundas y citas bíblicas, especialmente del Cantar de los Cantares. Por ejemplo, en los diálogos amorosos que sostiene con Jesús dice: «porque todo mi amado es para mí y yo toda para él» [Cantares 2] y él le contestaba: «Date prisa amada mía, paloma mía, hermosa mía y ven [Cantares 2, 10] para que vean los ángeles que tengo mis delicias con los hijos de los hombres». [Proverbios 8] ${ }^{23}$

Otra semejanza entre las dos mujeres fueron sus confrontaciones con el demonio. A ambas las maltrataba y torturaba causándoles intensos dolores y un permanente sufrimiento. Además, ambas estuvieron expuestas a sus tentaciones, que implicaban malos pensamientos, deseos injustificados y alejamiento de la religión. Ramos describe los embates demoniacos que sufría Catarina de la siguiente manera: «Se conjuraban en concilios las furias infernales y, repartidos en escuadrones o enjambres, volvían rebeldes a acometerla, unos persuadiéndola que estaba condenada; otros, que era santa; otros que engañaba a sus confesores; otros, que los dejase porque no sabían gobernarla; y los más a rendirla con violencias y martirios la quebrantaban, la molían, la aprensaban y la descoyuntaban de manera por todo el espacio de la noche, causando en ella tantos dolores juntos que por la mañana no podía vestirse ni aún moverse; pero el alma encendida en el amor de su Dios y de la obediencia, batallaba valiente con su cuerpo baldado y totalmente impedido y, reconociendo la imposibilidad, clamaba con fe y confianza al divino poder; llamaba en su ayuda a la Santísima Virgen, a sus ángeles y santos, contra tantos confederados enemigos» ${ }^{24}$.

El dominico fray Agustín Dorantes, calificador del Santo Oficio de la Inquisición, que fue uno de los dictaminadores, consideraba a Catarina «maestra mística» y

21. Ramos, Primera parte de los prodigios de la omnipotencia y milagros de la gracia en la vida de la venerable sierva de Dios Catharina de San Joan, parág. 341.

22. Ramos, Primera parte de los prodigios de la omnipotencia y milagros de la gracia en la vida de la venerable sierva de Dios Catharina de San Joan, parág. 32.

23. Ramos, Primera parte de los prodigios de la omnipotencia y milagros de la gracia en la vida de la venerable sierva de Dios Catharina de San Joan, parág. 86.

24. Ramos, Primera parte de los prodigios de la omnipotencia y milagros de la gracia en la vida de la venerable sierva de Dios Catharina de San Joan, parág. 132. 
afirma que sus revelaciones «frecuentes, admirables y en grande parte simbólicas» cumplen con «todas las señales, condiciones e indicantes discretivos, que observan por regla los maestros místicos» ${ }^{25}$.

La simbiosis entre los dos personajes se hace patente cuando Ramos afirma que Dios envió a Catarina, en espíritu, para ayudar a una beata llamada Juana de Irazoqui, hija de confesión de Ramos, quien le había solicitado «encontrarse con una santa Teresa en el mundo». Resulta significativo que Catarina se presentó ante Juana vestida con el hábito teresiano, que nunca usó en vida, y la ayudó a «subir a grande altura de perfección por un camino tan áspero como meritorio» ${ }^{26}$.

La teología mística anticipaba el espíritu de «modernidad» que se impondría en los siguientes siglos en Occidente. Implicaba la complementariedad entre una referencia experimental y la experiencia religiosa, que se alejaba de las formas arbitrarias y jerárquicas que habían caracterizado la relación con lo divino en el Medie$v^{27}$. La relación directa entre el místico y Dios restaba importancia al papel de los clérigos en la conducción de las almas, situación que Ramos aborda directamente en su obra. Apoyado en una cita de santa Teresa, sostiene que la dirección espiritual de Catarina provenía directamente del cielo, porque «hay pocos en el mundo que pueden ser padres espirituales de personas muy favorecidas de Dios, por ser muy delicado y sutil el lenguaje del Espíritu Santo y muy dificultosos de percibir y penetrar sus divinos impulsos, y que por eso acostumbra la inmensa Sabiduría instruir a semejantes almas por sí misma, no fiando de otro su magisterio ${ }^{28}$. Llega al extremo de censurar a los confesores que tuvo, que la afligieron, apretaron y pusieron a «punto de reventar» ${ }^{29}$ y la exonera por haberles ocultado algunas de sus experiencias místicas, ya que solo Dios «había de ser su maestro» ${ }^{30}$.

La experiencia mística permitía acceder directamente al conocimiento divino, sin necesidad de intermediarios, lo que restaba importancia a los clérigos, en particular a los teólogos. Ramos sostiene que Dios, a través de su divina luz, manifestaba a Catarina «sus tesoros y riquezas, sus secretos y los secretos del mundo, llegando a ver como presente lo distante, lo oculto y lo futuro; representándosele algunas veces las cosas como en la realidad sucedían, otras en semejanzas o enigmas y otras en oráculos o misterios, con tanta liberalidad que fuera imposible el referirlas» ${ }^{31}$.

25. Dorantes, «Aprobación del muy R. P. maestro fray Agustín Dorantes de la sagrada orden de predicadores», s/p.

26. Ramos, Tercera parte de los prodigios de la omnipotencia y milagros de la gracia en la vida de la venerable sierva de Dios Catharina de San Joan, parág. 77.

27. Vilanova, 1989, p. 685.

28. Ramos, Segunda parte de los prodigios de la omnipotencia y milagros de la gracia en la vida de la venerable sierva de Dios Catharina de San Joan, parág. 118.

29. Ramos, Segunda parte de los prodigios de la omnipotencia y milagros de la gracia en la vida de la venerable sierva de Dios Catharina de San Joan, parág. 37.

30. Ramos, Segunda parte de los prodigios de la omnipotencia y milagros de la gracia en la vida de la venerable sierva de Dios Catharina de San Joan, parág. 240.

31. Ramos, Segunda parte de los prodigios de la omnipotencia y milagros de la gracia en la vida de la venerable sierva de Dios Catharina de San Joan, parág. 122 y Primera parte de los prodigios de la omnipo- 
Esta espiritualidad intimista hacía superfluos muchos ritos y festividades religiosas que formaban parte de la tradición. Ramos da poca importancia a los aspectos ostensibles y ceremoniales de la religiosidad católica y critica acremente la sociabilidad que conllevaban muchas actividades religiosas. Subraya que las prácticas religiosas de Catarina se reducían a visitar distintas iglesias poblanas, principalmente la de la Compañía de Jesús, donde iba a escuchar misa, confesarse y comulgar. Solía llegar a horas en que había poca concurrencia y se escondía atrás de alguna banca para concentrase en la misa e interactuar con las imágenes de su devoción. Se abstenía de asistir y participar en fiestas religiosas, procesiones y otros actos eclesiásticos, y permanecía indiferente, e incluso tenía una actitud crítica, frente al boato y lujo que se lucían en muchos inmuebles, misas y festividades religiosas. Ramos contrasta este comportamiento con el de otras mujeres que iban a las iglesias y oratorios con «amigas y vecinas» y se entretenían en "conversaciones inútiles» o que «previniendo comidas con pretextos de velar, hacían del templo y casa de oración lugar de recreo a todos sus sentidos». Especialmente reprobables le parecían las mujeres que se comportaban así portando un hábito externo, como era el caso de muchas beatas. En su opinión ellas merecían que "Dios saliera de su tabernáculo y con un azote en la mano las echara de su templo» ${ }^{32}$.

Ramos afirma que dado el vínculo especial que Catarina tenía con Divinidad, la interacción mística podía suscitarse en cualquier lugar y no estaba sujeta a espacios sacros, como las ermitas, los conventos y los templos. Tampoco dependía de la presencia corporal de las imágenes para interactuar con ellas, ya que podía reunirse con ellas espiritualmente. Así en su hogar, la imagen de la virgen del Pópulo, perteneciente a la iglesia de la Compañía, solía bajar de su altar para ofrecerle leche de sus pechos - que ella rechazaba humildemente-, dejarle al Niño Jesús y retirarse a su nicho, «donde se le representaba sin el Niño Dios». Catarina tomaba al Niño en brazos, para venerarlo y adorarlo y lo guardaba «dentro de su corazón» ${ }^{33}$. Algunas festividades como la Semana Santa solía celebrarlas en la intimidad de su humilde hogar, donde rezaba y hacía penitencias, si bien «ordinariamente los confesores le mandaban que no asistiese el viernes santo ni aun a los divinos oficios, temerosos de que su corazón herido y lastimado [por vivir la pasión de Jesucristo] se turbase y se desmayase en la iglesia» ${ }^{34}$.

Estos rasgos de la espiritualidad teresiana fueron desaprobados con frecuencia por la Iglesia institucional, que sentía amenazada su autoridad y exclusividad en el tratamiento con lo divino. Tal vez fue una de las razones por las que la Inquisición condenó a numerosas beatas como «falsas místicas» y probablemente influyó para que la obra de Ramos y el culto a Catarina quedaran prohibidos. A causa de esta prohibición Catarina cayó en el olvido, Alonso Ramos acabó sus días desqui-

tencia y milagros de la gracia en la vida de la venerable sierva de Dios Catharina de San Joan, parág. 95. 32. Ramos, Primera parte de los prodigios de la omnipotencia y milagros de la gracia en la vida de la venerable sierva de Dios Catharina de San Joan, parág. 173 y 234.

33. Ramos, Primera parte de los prodigios de la omnipotencia y milagros de la gracia en la vida de la venerable sierva de Dios Catharina de San Joan, parág. 178.

34. Ramos, Primera parte de los prodigios de la omnipotencia y milagros de la gracia en la vida de la venerable sierva de Dios Catharina de San Joan, parág. 95. 
ciado y alcohólico y los poblanos se vieron privados de la posibilidad de tener una santa propia.

\section{BIBLIOGRAFÍA}

Bailey, Gauvin Alexander, «A Mughal Princess in Baroque New Spain. Catarina de San Juan (1606-1688), The China Poblana», Anales del Instituto de Investigaciones Estéticas, 19, 71, 1997, pp. 37-73.

Bieñko de Peralta, Doris, «Voces del claustro. Dos autobiografías de monjas novohispanas del siglo XVII», Relaciones, 35, 139, 2014, pp. 157-194.

Dorantes, Agustín, «Aprobación del muy R.P. maestro fray Agustín Dorantes de la sagrada orden de predicadores», en Alonso Ramos, Primera parte de los prodigios de la omnipotencia y milagros de la gracia en la vida de la venerable sierva de Dios Catharina de San Joan, Puebla, Imprenta Plantiniana de Diego Fernández de León, 1689, s/f.

Francia Vaca, Joseph de, «Aprobación del señor doctor don Joseph de Francia Vaca, cura...», en Alonso Ramos, Primera parte de los prodigios de la omnipotencia y milagros de la gracia en la vida de la venerable sierva de Dios Catharina de San Joan, Puebla, Imprenta Plantiniana de Diego Fernández de León, 1689, s/f.

Gómez de la Parra, José, Fundación y primer siglo. Crónica del primer convento de carmelitas descalzas en Puebla. 1604-1704, México, Universidad Iberoamericana/Comisión Puebla Quinto Centenario, 1992.

Jaffary, Nora, «El tratado espiritual de María Josefa de la Peña», en Diálogos espirituales. Manuscritos femeninos hispanoamericanos. Siglos XVI-XIX, Puebla, Benemérita Universidad Autónoma de Puebla/Universidad de las Américas Puebla, 2006.

Lavrin, Asunción, «Santa Teresa en los conventos de monjas de Nueva España», Hispania Sacra, 67, 136, 2015, pp. 505-529.

Madre de Dios, fray Agustín de la, Tesoro escondido en el Santo Carmelo mexicano. Mina rica de ejemplos y virtudes en la historia de los carmelitas descalzos de la provincia de la Nueva España, México, Probursa y Universidad Iberoamericana, 1984.

Maza, Francisco de la, Catarina de San Juan, princesa de la India y visionaria de Puebla, México, Consejo Nacional para la Cultura y las Artes, 1991.

Morgan, Ronald J., Spanish American Saints and the Rethoric of Identity, 16001810, Tucson, The University of Arizona Press, 2002.

Myers, Kathleen Ann, Neither Saints nor Sinners. Writing the lives of Women in Spanish America, Oxford, Oxford University Press, 2003.

Myers, Kathleen Ann, «¿Testimonio para la canonización o prueba de blasfemia? La Inquisición de Nueva España y la hagiografía de Catarina de San Juan», 
en Mujeres en la Inquisición. La persecución del Santo Oficio en España y el Nuevo Mundo, ed. Mary E. Giles, Barcelona, Martínez Roca, pp. 326-356.

Núñez de Miranda, Antonio, «Carta y discurso preocupativo sobre algunas dificultades que pueden resaltar luego de la primer vista de esta historia», en Alonso Ramos, Primera parte de los prodigios de la omnipotencia y milagros de la gracia en la vida de la venerable sierva de Dios Catharina de San Joan, Puebla, Imprenta Plantiniana de Diego Fernández de León, 1689, s/f.

Ramos, Alonso, Primera parte de los prodigios de la omnipotencia y milagros de la gracia en la vida de la venerable sierva de Dios Catharina de San Joan, Puebla, Imprenta Plantiniana de Diego Fernández de León, 1689.

Ramos Alonso, Segunda parte de los prodigios de la omnipotencia y milagros de la gracia en la vida de la venerable sierva de Dios Catharina de San Joan, México, Imprenta de Diego Fernández de León, 1690.

Ramos Alonso, Tercera parte de los prodigios de la omnipotencia y milagros de la gracia en la vida de la venerable sierva de Dios Catharina de San Joan, México, Imprenta de Diego Fernández de León, 1692.

Ramos, Manuel, Místicas y descalzas, México, Centro de Estudios de Historia de México CONDUMEX, 1997.

Rice, Robin Ann, «Hacia una poética de las hagiografías novohispanas. El caso de la "vida" de Catarina de San Juan de Alonso Ramos», Perífrasis. Revista de literatura, teoría y crítica, 5, 10, 2014, pp. 125-139.

Rubial García, Antonio, «Los santos milagreros y malogrados de la Nueva España», en Manifestaciones religiosas en el mundo colonial americano, coord. Clara García Ayluardo y Manuel Ramos Medina, vol. 1, México, Instituto Nacional de Antropología e Historia, Universidad Iberoamericana y Centro de Estudios de Historia de México CONDUMEX, 1997, pp. 51-88.

Rubial García, Antonio, «Los santos fallidos y olvidados; los venerables contemporáneos de sor Juana», en Sor Juana Inés de la Cruz y sus contemporáneos, ed. Margo Glanz, México, Universidad Nacional Autónoma de México, 1998, pp. 29-44.

Rubial García, Antonio, La santidad controvertida. Hagiografía y conciencia criolla alrededor de los venerables no canonizados de Nueva España, México, UNAM/FCE, 1999.

Rubial García, Antonio, Profetisas y solitarios. Espacios y mensajes de una religión dirigida por ermitaños y beatos laicos en las ciudades de Nueva España, México, UNAM/FCE, 2006.

Rubial García, Antonio, «La hagiografía. Su evolución histórica y su recepción historiográfica actual», en De sendas brechas y atajos. Contexto y crítica de las fuentes eclesiásticas, siglos XVI-XVIII, coord. Doris Bieñko y Berenise Bravo, México, Escuela Nacional de Antropología e Historia, 2008, pp. 15-33. 
Sigüenza y Góngora, Carlos de, Paraíso occidental, prólogo Margarita Peña, México, Consejo Nacional para la Cultura y las Artes, 1995.

Vidal, Joseph, «Parecer de Joseph Vidal, professo de cuarto voto de la compañía de lesus», en Alonso Ramos, Segunda parte de los prodigios de la omnipotencia y milagros de la gracia en la vida de la venerable sierva de Dios Catharina de San Joan, México, Imprenta de Diego Fernández de León, 1690, s/f.

Vilanova, Evangelista, Historia de la teología cristiana. Prerreforma, reformas, Contrarreforma, vol. 2, Barcelona, Herder, 1989. 